\title{
Ubu Rei: Uma participação latino-americana na PQ19
}

\author{
Desirée Bastos de Almeida \\ Universidade Federal do Rio de Janeiro - UFRJ, Rio de Janeiro/RJ, Brasil \\ E-mail: desireebastos@hotmail.com
}

\section{Resumo}

Este artigo pretende descrever o processo de criação, desenvolvimento e viabilização do projeto Ubu Rei, único projeto latino-americano apresentado na mostra Common Design Project da seção PQStudio da Quadrienal de Praga de 2019. O projeto foi criado por Igor Avelino e Rafael Torres, estudantes da Escola de Belas Artes da Universidade Federal do Rio de Janeiro, orientados pela Profa. Desirée Bastos.

\section{Palavras-chave}

PQ2019. Common Design Project. Ubu Rei.
This paper aims to describe the creating, developing and enabling process of the Ubu Rei Project, the only Latin American project presented at PQStudio section of Prague Quadrienal 2019. The project was created by Igor Avelino and Rafael Torres, students from the School of Fine Arts of Federal University of Rio de Janeiro, leaded by Professor Desirée Bastos.

Keywords

PQ2019. Common Design Project. Ubu Rei. 


\section{Introdução}

A Quadrienal de Praga ${ }^{1}$ vem comportando cada vez mais um grande número de eventos como palestras, workshops e exposições, os quais contemplam uma enorme variedade de interesses e tipos de produção. Existem várias subdivisões no encontro quadrienal, que abriga desde as exposições fixas dos países e regiões, exposições temáticas com curadoria feita pelos membros da quadrienal, workshops, espaço dedicado às crianças, mostra dos estudantes por países, debates, conferências, até um festival de performance. São dez dias de uma intensa programação, que nos proporciona uma experiência de maratona do espetáculo.

Desde 2003, a Quadrienal abriu espaço para uma participação mais ativa do público em formação. A Scenofest (2003-2011) nascida como um setor dedicado aos estudantes de cenografia, deixou um grande legado de eventos dentro da Quadrienal. Voltada não somente para a formação, ela também busca dar maior visibilidade ao trabalho dos futuros designers da performance.

Como desdobramento da Scenofest, em 2015 tivemos o Spacelab, que em 2019 passou a se chamar PQStudio. Em 2019 o PQStudio retoma uma mostra que aconteceu em 2007 na Scenofest, chamada The Birds, cuja ideia era promover uma exposição de trabalhos de estudantes do mundo inteiro. O tema central era desenvolver um projeto de cenografia, figurino ou arquitetura teatral para a peça Os Pássaros de Aristófanes.

Parte do PQStudio, a mostra Common Design Project foi assim batizada por se tratar também de uma exposição de temática única. Esta tinha por tema a peça Ubu Rei de Alfred Jarry (2007). Junto à exposição dos trabalhos, foi proposto um mini colóquio de três dias para que houvesse uma fala de cada estudante sobre seu processo de criação do projeto. Uma ideia semelhante à de 2011 no DISK

\footnotetext{
1 Site Prague Quadrennial. Disponível em: < http://www.pq.cz >. Última consulta em: 13 set. 2019.

Catálogo Quadrienal de Praga 2007. Editores: PQ2007 Team. ISBN:9788070082126; 350 páginas. Idioma: Inglês e Checo, 2007.

Catálogo Quadrienal de Praga 2011. Editores: Sodja Lotker, Daniela Parizková, Ales Rumpel, Barbora Prihodová e curadores dos projetos individuais. ISBN: 978-80-7008-259-1; 328 páginas. Idioma: Inglês, 2011.

Catálogo Quadrienal de Praga 2015. Editores: Sodja Lotker, Daniela Parizková, Ondrej Svoboda, Lucie Cepcová e curadores dos projetos individuais. ISBN: 978-80-7008-350-5; 400 páginas. Idioma: Inglês e Checo, 2015.
}

Stories - parte da Scenofest daquele ano - espaço que previa uma discussão dos trabalhos logo após sua apresentação. O conceito por trás da conversa ou explanação da obra apresentada era servir como catalizador de reflexões entre estudantes e educadores, e assim adentrar os espaços reais e imaginários nos quais os futuros designers situam, exploram e criam dentro de suas práticas individuais. $\mathrm{Na}$ apresentação do projeto no site da Quadrienal de Praga (www.pq.cz), a curadoria da mostra feita por Patrick Du Wors reforça esta ideia quando justifica que, além de montar e apresentar suas obras individualmente, cada universidade teria a possibilidade de criar um espaço de conversas. Ao invés de privilegiar somente o texto ou abordagem de sua encenação, as discussões se debruçariam especialmente sobre a natureza da arte e design da performance. Através de uma série de rodas de discussão conduzidas por designers de várias partes do mundo, entre eles Tom Piper (Reino Unido), Freshteh Rostanour (Iran/ EUA), Samuel Wang (Taiwan), Eloise Kazan (Croacia/ Mexico), as trocas de ideias poderiam se expandir em uma plataforma internacional, fomentando um maior intercâmbio entre as próximas gerações de designers da performance.

A chamada para inscrições era aberta a quaisquer universidades nos cinco continentes, e deveria ser feita individualmente por cada universidade e diretamente à curadoria do projeto, sem a intermediação da curadoria nacional da mostra Países e Regiões. Ou seja, se a Universidade tivesse mais de um projeto sendo desenvolvido, esta deveria selecionar qual deles iria representá-la no ato da inscrição. Este processo estimulava a participação de dois ou mais cursos dentro de uma mesma instituição.

Além disso, no Common Design Project poderiam participar cursos de graduação e pós-graduação. Após uma pré-inscrição no site da Quadrienal de Praga, os projetos desenvolvidos nas disciplinas da universidade eram enviados para apreciação e seleção pelos membros da equipe curatorial.

O fato de desenvolvermos o projeto como parte de nossas disciplinas na universidade propicia uma dupla exposição em um evento deste porte: se por um lado a produção artística dos estudantes é exposta, também os processos acadêmicos da instituição e de seus professores/orientadores são evidenciados em âmbito internacional.

O curso de Artes Cênicas da Universidade Federal do Rio de Janeiro é voltado exclusivamente ao design da performance nas áreas de Cenografia e Figurino. Ele está alocado na Esco- 
la de Belas Artes e tem uma grade de disciplinas que permeia todo um conjunto de saberes relativos às artes plásticas, artes cênicas e artes aplicadas. Existe também um leque de disciplinas que permite propor conteúdos variados de acordo com o desejo do docente. Estas disciplinas contam como créditos complementares para o estudante.

Neste cenário pude oferecer no segundo semestre de 2018 uma disciplina chamada Tópicos especiais em performance, na qual pretendia explorar o conhecimento de técnicas artesanais de malharia (tricô e crochê) para criar estruturas que servissem tanto para vestir o corpo, quanto para vestir o espaço. Naquele momento, contamos com a parceria do Centro Carioca de Design, que nos cedeu o espaço de trabalho, já que após o incêndio sofrido pela Escola de Belas Artes em 2016 ainda continuávamos sem espaços adequados para lecionar.

Visando a participação no Common Design Project na PQ2019, foi proposta uma nova abordagem da obra Ubu Rei, uma reelaboração de seu discurso através do desenvolvimento plástico que as técnicas de malharia propõem.

Era solicitado no site da $P Q$ que os projetos contemplassem um projeto completo de performance de Ubu Rei incluindo cenografia, figurinos, iluminação, design de som e direção. A chamada também estimulava a reunião de mais de um curso dentro da universidade em um trabalho coletivo, pois apenas seria aceita uma inscrição por instituição.

$\mathrm{Na}$ época conversei com alguns colegas da UFRJ sobre o projeto, porém nenhuma parceria se firmou. Decidi por continuar este processo apenas em minha disciplina de tópicos especiais e fazer a inscrição com o produto que conseguíssemos desenvolver. Eu tinha um escopo limitado no espaço de atuação da disciplina, além de poucos alunos. Dois deles, Igor Avelino e Rafael Torres, aceitaram desenvolver um trabalho inspirado em Ubu Rei.

Inicialmente, lemos o texto e fizemos apontamentos sobre suas ideias centrais. Naquele momento, estávamos em meio às eleições presidenciais de 2018 e era impossível não relacionar a disputa de poder às formas tirânicas de governar apontadas na obra de Jarry. O objetivo principal das primeiras orientações dadas à turma era focar nas técnicas desenvolvidas em sala de aula, para então, explorar as possibilidades da transformação de ideias e conceitos em materiais e objetos. Os objetos deveriam ter a capacidade de comunicar apenas através da leitura de sua imagem. Este tipo de percurso - de focar no micro e ir aos poucos expandindo para o macro - é para mim primordial para o alcance de uma polissemia visual.

Na malharia, para desenvolvermos um objeto, podemos também inicialmente criar o material do mesmo. Com as sobreposições destes materiais criados, constrói-se uma teia capaz de constituir um grande universo estimulante à leitura da imagem final.

A partir desta estrutura decidimos criar vestíveis (um híbrido entre máscara, figurino e instalação) que servissem a uma ressignificação deste texto. Estes objetos deveriam ser capazes de estimular no espectador o espírito de Ubu Rei. Também tínhamos à nosso favor o fato de que a peça de Jarry é a grande fundadora da cena moderna, dando um passo à frente em relação ao teatro simbolista rumo ao teatro surrealista. Portanto, não faria sentido desenvolvermos um projeto de encenação tão esquemático e formal segundo o ponto de vista de uma encenação realista do século XIX. A própria ideia de cenografia inicial de Ubu Rei deveria representar "O lugar algum". Sendo assim, preferimos valorizar a criação deste objeto/figurino/máscara/instalação para a AÇÃO.

Por conseguinte, o projeto nasce de uma proposta plástica a partir da poética própria da técnica de malharia. Ao mesmo tempo que se instaura por laços fortes, pode ser desmanchada facilmente com um puxar de fios. Nesta técnica reside toda a efemeridade de uma performance, ou também a efemeridade das relações de poder tratadas com maestria em Ubu Rei. Ao mesmo tempo em que Pai Ubu governa, já existem forças opostas prontas para depor seu trono. Isso mostra bem como se dão as relações do poder e todas as estratégias de manutenção do mesmo. Não há garantia de permanência, o que existe é uma eterna relação de fazer e desfazer.

Figura 1 - Prancha parte do projeto conceitual apresentado na exposição Common Design Project PQ19.

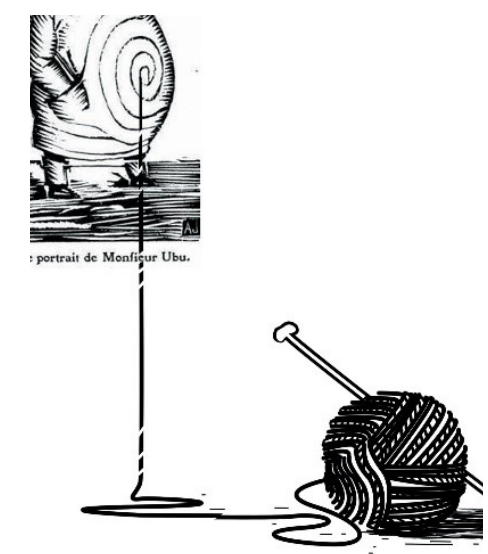

Fonte: Desirée Bastos, Igor Avelino e Rafael Torres. 
Como o início da malharia é sempre o fio, solicitei aos estudantes uma proposta de fios inovadora que pudesse trabalhar as ideias do texto. Foi então que um dos estudantes, Rafael Torres, propôs o uso da ráfia de plástico verde musgo usada para amarrar mercadorias e do saco de lixo preto cortado em tiras.

O fio de saco preto simboliza os sacos para cobrir cadáveres. Além disso, o plástico também é um grande símbolo de vilania para com o meio ambiente. $\mathrm{O}$ estudante apresentou posteriormente também a ideia da fita zebrada. Esta fita é usada como fita de alerta de segurança ou como isolamento de cenas de crime, podendo assumir a simbologia do terror implantado por governos autoritários. $\mathrm{O}$ resultado da trama deste fio específico mescla as cores preto e amarelo e nos dá uma terceira imagem: o camuflado dos exércitos: força autorizada pelo governo a oprimir por meio da extrema violência.

Figura 2 - Prancha parte do projeto conceitual apresentado na exposição Common Design Project PQ19.

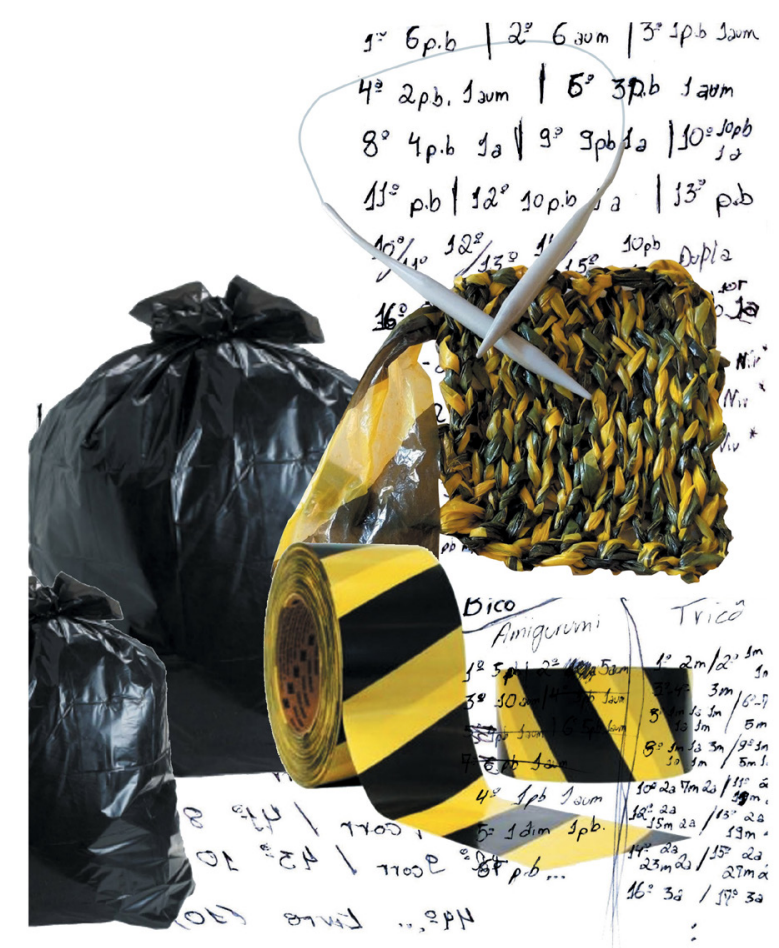

Fonte: Desirée Bastos, Igor Avelino e Rafael Torres.

Após a proposição de fios feita pelo estudante supracitado, sugeri que os demais trabalhos fossem feitos com os mesmos fios para termos uma unidade entre Pai e Mãe Ubu.

Em relação à forma de Pai Ubu, pensamos em algo que se assemelhasse a um abutre existente na América do Sul, uma ave chama- da Urubu-rei (fazendo uma cacofonia com o título da peça), a maior ave necrófaga da América do Sul. Essa relação com a morte, com a alimentação de restos de cadáveres, é outra analogia à imagem do abutre que ultrapassa a cacofonia.

Naturalmente a imagem do Urubu-rei nos conduziu também à imagem do então candidato à presidência da República, Jair Bolsonaro. Ubu Rei é um texto que mostra a tirania do pequeno burguês quando dispõe de poder. Ele é praticamente uma profecia política. Além disso, o Pai Uubu é retratado por Jarry com um bufo, um grande idiota. Ele antecipa o arquétipo dos ditadores cruéis do século XX e suas neo variações estúpidas contemporâneas. Pai Ubu se torna rei devido à sua bestialidade e violência sem limites.

Mãe Ubu foi pensada como uma força anexa ao seu marido, pois não somente compactua com todas as formas de manutenção de poder por meio da violência, mas também estimula Pai Ubu a matar o rei da Polônia para usurpar seu trono, assim como na famosa relação de Macbeth e Lady Macbeth. Enquanto trabalhou-se com a ideia da cabeça, do bico de ave necrófaga para Pai Ubu, Mãe Ubu ficou com as partes anexas ao bico como uma crista carnuda pendente, própria desta espécie de ave. Esta característica morfológica específica do Urubu-rei também nomeia o gênero ao qual ele pertence: Sarcoramphus².

Figura 3 - Prancha parte do projeto conceitual apresentado na exposição Common Design Project PQ19.

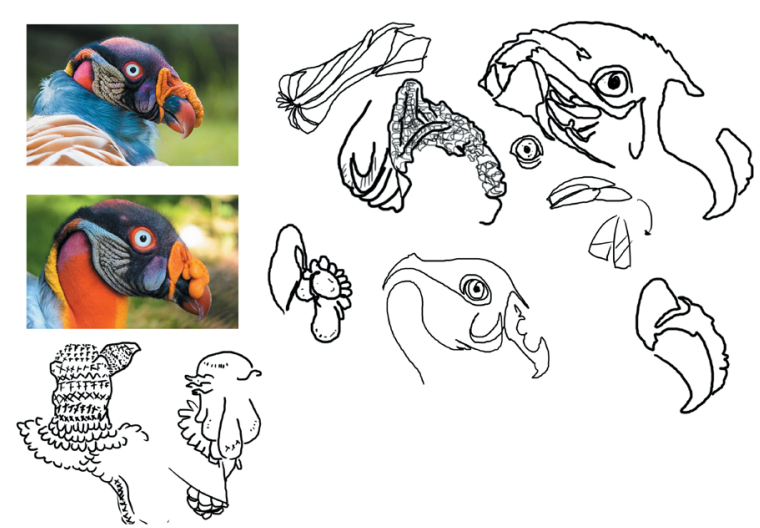

Fonte: Desirée Bastos, Igor Avelino e Rafael Torres.

Diante disso, a proposta de encenação é mais ligada a uma instalação performática, que consiste em condensar a história na tirania do casal Ubu e substituir as outras personagens pelo próprio es-

2 Junção dos termos gregos sárx (carne) e rámphos (bico). Disponível em: < http://pt.m.wikipedia.org/wiki/Urubu-rei >. Acesso em: 23 out. 18 . 
pectador à medida que este assume o lugar ativo na performance. Os corpos do casal Ubu são uma espécie de máscara com um prolongamento vestível, que proporciona uma experiência da perspectiva interna das personagens. Cada espectador poderia incorporar Pai Ubu e Mãe Ubu. A ideia de espectador que ajuda a criar a obra comunica-se fortemente com o universo dos parangolés de Hélio Oiticica. $\mathrm{O}$ fato de propormos uma mudança de papéis ao entrar e sair dos corpos de Pai e Mãe Ubu dialoga com a ideia de que exercemos um papel duplo na sociedade: ora tiranos, ora tiranizados. Este papel foi muito bem detalhado pelo filósofo francês Étienne de la Boétie (2017) em seu livro Discurso da servidão voluntária, onde ele afirma que os tiranos apenas têm o poder que têm, pois abaixo deles existe uma população inteira que lhes outorga este poder. E completa sustentando que a população se submete à tirania, pois dentro de cada ser humano reside um pequeno tirano apenas esperando o momento de tiranizar quem está abaixo. Suportamos a tirania em troca da esperança de tiranizar. Portanto, a ideia deste trabalho era propor uma residência na cabeça de Pai e Mãe Ubu, a ponto de o público poder se ver tanto como tirano, quanto na perspectiva do tiranizado.

Chegamos a este ponto do projeto no final do segundo semestre de 2018, quando deveríamos formatar uma apresentação de até 5 pranchas explicando todas as etapas de realização para a curadoria do Common Design Project. Fizemos uma sessão de fotos das máscaras prontas com os próprios designers como modelos, escolhemos uma direção de arte para as pranchas utilizando um fundo cinza, as fitas zebradas e as cores militarizadas e enviamos o material. Sabíamos que seria muito difícil termos êxito na seleção, já que nossa proposta não era uma proposta convencional de encenação e tampouco contemplava tudo o que era solicitado no edital: cenografia, luz, direção, sonoplastia.
Figura 4 - Prancha parte do projeto conceitual apresentado na exposição Common Design Project PQ19.

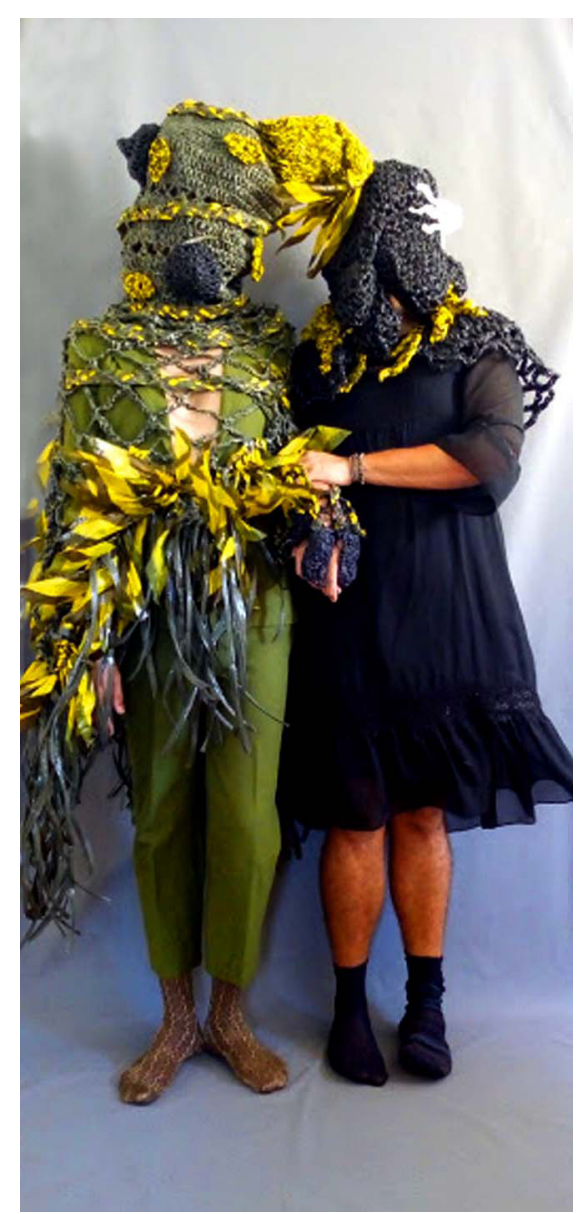

Fonte: Desirée Bastos, Igor Avelino e Rafael Torres.

Para nossa surpresa, o projeto foi aprovado. Imagino que o impacto das imagens enviadas tenha sido fundamental para este aceite. O resultado estético de fato foi impressionante. Isto se deve a um processo: uma minuciosa pesquisa visual e de materiais e a uma maestria na realização técnica da proposta feita pelos estudantes. Outra surpresa gratificante foi o fato de termos sido o único projeto da América Latina a ser selecionado. Das 35 universidades participantes foram selecionadas 15 , entre elas: Victorian College of the Arts (Austrália), Tel Aviv University (IL), The University of Melbourne (AU), Theatre Ronin (HK), Moscow Art Theatre School (RU), Institute of Art Design \& Technology (IE), Holy Spirit University of Kaslik (LB), London College of Fashion (UK), Cracow University of Technology (PL), California Institute of the Arts (USA), Academy of Dramatic Arts/ University of Zagreb (HR), Carnegie Mellon University (USA), The Royal Central School of Speech and Drama/ University of London (UK) e University of Arizona (USA), além da UFRJ (BRA). 
A seleção veio com um questionamento da curadoria internacional sobre nossa proposta de cenografia, iluminação e encenação, já que no projeto enviado existia apenas a criação e conceituação das mácaras/vestíveis. Porém, o projeto não continha uma descrição sobre o uso delas. Foi neste momento que nos reunimos novamente para continuarmos o desenvolvimento de mais camadas para a encenação, como a criação de uma sonoridade e de um espaço para inserir as máscaras. Naquele momento o que realmente importava era qual seria a ação que proporíamos ao público. Após muitas conversas, decidimos que o lugar das máscaras seria a rua e que não caberia uma construção cenográfica, especialmente pelo teatro estabelecido por Jarry. Para ele, o texto trabalha com a ideia da palavra que evoca os espaços.

Em meados de maio começaram enormes movimentos populares de protesto contra os cortes estabelecidos pelo novo governo federal impostos à educação. Pensamos que seria o melhor momento para levar as máscaras às ruas e experimentar as reações dentro da manifestação. Na rua encontraríamos a população mais carente, que muitas vezes não tem acesso à arte, sendo também a camada da população que mais sofre com os cortes orçamentários do governo. $15 \mathrm{M}$ foi chamado este dia, quando em muitas capitais do Brasil estudantes, professores e trabalhadores foram às ruas em protesto.

Figura 5 - Imagem de 15M19, Candelária.

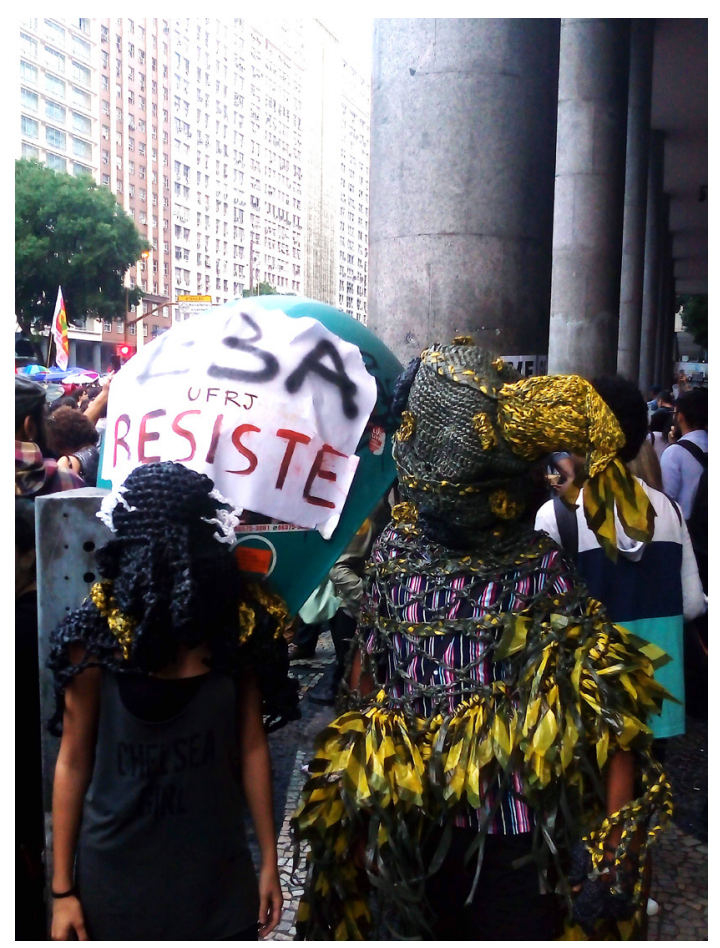

Fonte: Desirée Bastos.
As figuras despertaram uma enorme curiosidade, pois pareciam deslocadas do contexto. Porém, o fato das pessoas se aproximarem, questionarem e quererem participar já foi suficiente para iniciarmos discussões sobre as questões propostas pelo trabalho. Pouco depois, descobrimos que uma lei de 2013 proíbe o uso de máscaras em passeatas e manifestações, algo que poderia ter inclusive enriquecido a discussão.

Ao final, percebemos que uma intervenção sonora teria sido muito importante para explicarmos menos o projeto e causarmos mais interpretações e conexões da população com a obra. Criamos então, no interior das máscaras, um dispositivo sonoro com um fone de ouvido. Ao vestir a máscara, o espectador/ator entraria em contato não somente com o "corpo" de Pai e Mãe Ubu, mas especialmente com seus pensamentos.

Decidimos sonorizar as máscaras com uma compilação dos discursos carregados de ódio proferidos nas últimas eleições brasileiras. Reunimos muitas falas de Jair Messias Bolsonaro para contextualizar o ato de vestir a máscara. Seria como estar na pele e nos pensamentos deste personagem e, eventualmente, identificar-se como o locutor de algumas destas falas.

\section{Preparativos para Praga}

Para a exposição em Praga recebemos uma planta do espaço expositivo e uma listagem dos itens de suporte oferecidos para expor o trabaIho: dois painéis em OSB de $1,25 \mathrm{~m} \times 2,20 \mathrm{~m}$ em $\mathrm{L}$, dois manequins e uma luminária amarela e a distribuição desses equipamentos já em planta baixa.

Figura 6 - Layout do espaço expográfico em Praga.

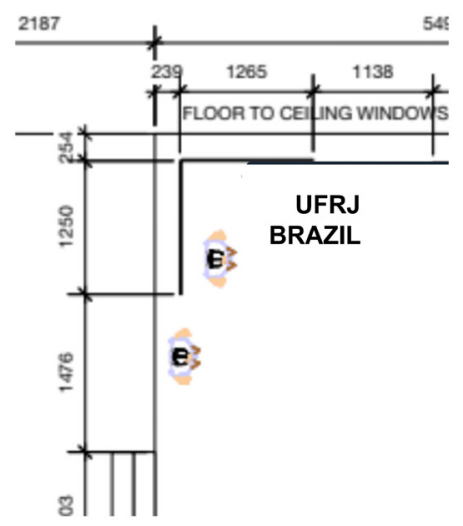

Fonte: Time do Common Design Project. 
Foi solicitado que se respeitasse à risca todas as instruções da planta baixa. Tínhamos o desejo de não usar manequins para possibilitar a vestibilidade e interação com as máscaras, mas não foi permitido pela organização desviar do projeto expográfico original. Portanto, decidimos colocar fones de ouvido externos para ao menos possibilitar a escuta dos pensamentos das máscaras. Também para contextualizar um público estrangeiro, acrescentamos os discursos de Donald Trump aos áudios. Por fim, foi um paralelo excelente com Bolsonaro, já que este se diz abertamente um grande fã de Donald Trump.

Inserimos no projeto expositivo fotografias de

$15 \mathrm{M}$. Fizemos um projeto plástico inspirado na arte urbana que usa a técnica de lambe-lambe ${ }^{3}$, para assim sobrepor imagens das pessoas no protesto e causar na cenografia a impressão de uma continuação da experiência da rua. Nesta estética de colagem, também acrescentamos imagens do processo de criação do projeto como um todo, além de frases de Étienne de la Boétie para estimular a reflexão central do projeto.

Figura 7 - Projeto expográfico apresentado na PQ19.

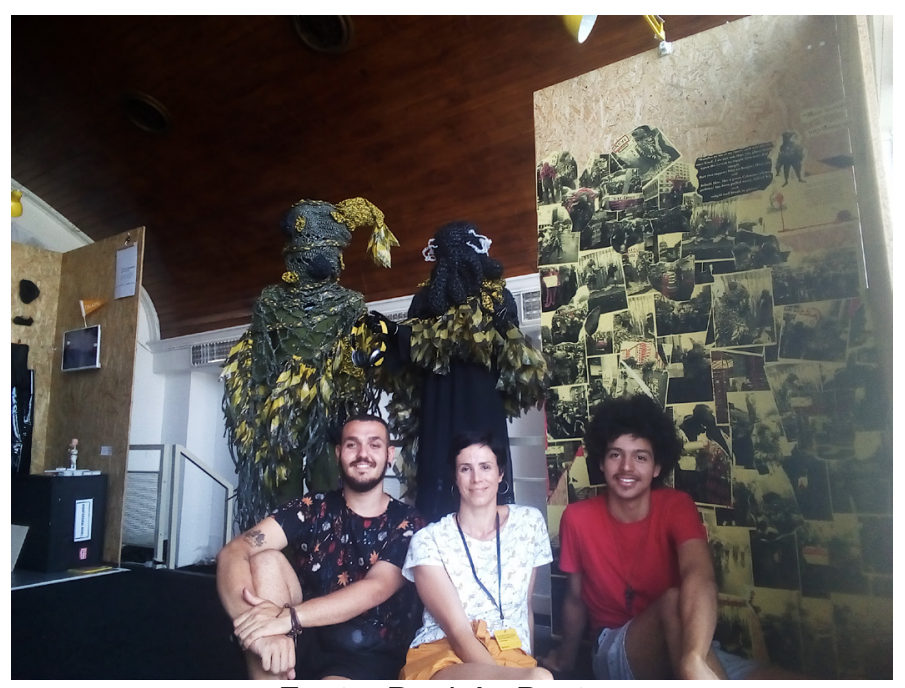

Fonte: Desirée Bastos.

\section{Apresentações}

A montagem da exposição foi no dia 12 de junho. Ocorreram três dias de apresentações dos projetos sempre pela manhã, entre 13 e 15 de junho. Tendo em média 30 minutos cada, as apresentações não eram agendadas, sendo escolhidas aleatoria-

3 "Poster lambe-lambe, é um poster artístico de tamanho variado que é colado em espaços públicos. Quando feitos em série, sua reprodução pode ser através de foto copiadoras ou silk screen". Disponível em: < http://pt.m.wikipedia.org/wiki/Poster_Lambe-lambe >. Acesso em: 12 set. 2019. mente pelos professores curadores da exposição. Isso obrigava todos os participantes a acompanhar todas as apresentações, fato bastante produtivo, especialmente no intercâmbio entre os estudantes e professores das universidades participantes. Nosso projeto foi extremamente bem recebido pelos participantes da mostra e pelo público visitante, tendo recebido diversos elogios da equipe curatorial.

Após todo um processo de desafios na elaboração do projeto, prazos curtos para submetê-lo e incertezas na espera de um resultado - muitas vezes alimentadas por uma supervalorização da produção estrangeira - os resultados artísticos e sua receptividade na mostra provaram que é possível viabilizar um projeto com qualidade em meio a enormes dificuldades. Para possibilitar a ida do trabalho e para permitir viagem dos dois estudantes a Praga, muitas dificuldades foram enfrentadas, especialmente financeiras. Tivemos de criar estratégias diversas para reunir os recursos necessários. Com a ajuda de muitos professores, amigos, familiares, uma campanha de financiamento coletivo na internet e um pequeno apoio financeiro da Escola de Belas Artes da UFRJ, a viagem foi viabilizada. É importante ressaltar que, mesmo em meio à crise financeira que vivem as universidades públicas, a UFRJ entendeu que seria de grande relevância ter um representante da EBA em um evento desta magnitude.

Nesta urgência de providências práticas paralela a desafios artísticos complexos reside um imenso aprendizado, especialmente para aqueles que precisam viabilizar suas vidas como artistas em um mercado cada vez mais precarizado e marginalizado.

Avalio que o trabalho desenvolvido em sala de aula para a criação deste projeto pelos estudantes pareça ser parte muito pequena neste mundo de experiências vividas na Quadrienal, porém foi de vital importância. Os ensinamentos de malharia propiciaram uma estética diferenciada ao trabalho, impulsionaram novas ideias, e foram o ponto de partida para uma grande oportunidade. O maior aprendizado esteve na persistência premiada por uma grande experiência na Quadrienal.

Referências

BOÉTIE, Étienne de la. Discurso da servidão voluntária. Ed. Martin Claret, São Paulo, 2017.

JARRY, Alfred. Ubu Rei. Tradução: Sergio Flaksman, Coleção: Grandes Dramaturgos, Ed. Peixoto Neto, São Paulo, 2007. 
Recebido: 30/09/2019

Aprovado: 25/03/2020 